\title{
DYLEMATY PRZY USTALANIU STANU PRZESYCENIA RUCHEM WLOTÓW SKRZYŻOWAŃ Z SYGNALIZACJĄ ŚWIETLNĄ
}

\begin{abstract}
Przedmiotem artykułu jest analiza dokładności szacowania średnich długości kolejek pojazdów na wlotach skrzyżowań z sygnalizacją świetlną, za pomocą modeli matematycznych stosowanych w Polsce i w USA. Na podstawie badań stwierdzono, że w przypadku dużego nasycenia ruchem lub przesycenia wlotu błędy szacowania długości kolejek są bardzo znaczące. Główną przyczyną tego jest brak lub niewłaściwy sposób wyznaczania tzw. ,początkowej” kolejki pojazdów, formowanej w poprzednich cyklach sygnalizacyjnych w stosunku do cyklu analizowanego.
\end{abstract}

Słowa kluczowe: kolejki pojazdów, sygnalizacja świetlna, zatłoczenie

\section{Wprowadzenie}

Znaczne zatłoczenie ruchem oraz tworzenie się długich kolejek pojazdów przed wlotami skrzyżowań są dzisiaj typowym obrazem warunków ruchu w średnich i dużych miastach Polski. Konsekwencją tego jest wzrost wypadkowości oraz ponoszenie znacznych strat czasu w podróży. Jak wyliczają Autorzy pracy [1], z powodu zatłoczenia (zatory oraz utrudnienia w ruchu drogowym), na sieci ulicznej największych polskich miast ,pracujący kierowcy” stracili w 2015 roku 3,8 mld złotych, co stanowiło średnio $70 \%$ ich jednej pensji. Ponadto odnotowano wzrost tego wskaźnika aż o $12 \%$ w stosunku do wartości z roku 2014. Na poziomie mikroekonomicznym koszt występującego na sieci ulicznej zatłoczenia dla statystycznego „mieszkańca-kierowcy” wyniósł w tych miastach 3350 zł w skali roku (w stosunku do roku 2014 jest to wzrost o około 17\%). Szacunki Autorów Raportu [1] wskazują, że roczny koszt zatorów drogowych dla gospodarki kraju (po odjęciu dochodów podatkowych) był równy 3,3 mld zł, czyli 0,19\% PKB.

\footnotetext{
${ }^{1}$ Autor do korespondencji/corresponding author: Damian Iwanowicz, Uniwersytet TechnologicznoPrzyrodniczy, Al. Prof. S. Kaliskiego 7, 85-796 Bydgoszcz; Katedra Inżynierii Drogowej i Transportu, e-mail: damian.iwanowicz@utp.edu.pl

${ }^{2}$ Tomasz Szczuraszek, Uniwersytet Technologiczno-Przyrodniczy, Al. Prof. S. Kaliskiego 7, 85-796 Bydgoszcz, Katedra Inżynierii Drogowej i Transportu, e-mail: zikwb@utp.edu.pl
} 
Poszukiwanie sposobów minimalizowania zatłoczenia wymaga między innymi wiedzy o procesie tworzenia się kolejek pojazdów. Szczególnie dotyczy to wlotów skrzyżowań z sygnalizacją świetlną, ponieważ one najczęściej tworzą najważniejsze ogniwa podstawowej sieci ulic dużych i średnich miast. Na ten sam aspekt zwracają także uwagę Autorzy Raportu [1], którzy za główne źródło problemu wskazują tzw. „wąskie gardła” sieci ulicznej - czyli wloty dużych skrzyżowań.

W niniejszej pracy autorzy postanowili skonfrontować aktualne sposoby określania długości kolejek pojazdów na wlotach skrzyżowań z sygnalizacją świetlną z wartościami empirycznymi. Dokładność obliczeń tych kolejek ma bowiem olbrzymie znaczenie na poprawność ustalania warunków ruchu oraz stanu nasycenia ruchem i tym samym na szczegółowe rozwiązania projektowe infrastruktury drogowej oraz organizacji ruchu drogowego.

\section{Charakterystyka analizowanych metod obliczeniowych}

Analizie poddano metodologię obliczania długości kolejek pojazdów zawartą w polskich wytycznych (MOPS2004) [2] oraz amerykańskich z roku 2000 (HCM2000) [3] i z 2010 roku (HCM2010) [4]. Wynika to z faktu, iż wzory zawarte w wytycznych krajowych bazują w dużym stopniu na metodologii opracowanej w HCM2000. Ponadto, wytyczne HCM uznawane są w środowisku inżynierów ruchu za jedne z najważniejszych na świecie.

Zarówno metoda krajowa, jak i amerykańska HCM2000 posiadają modele obliczeniowe do wyznaczenia średnich długości kolejek pojazdów, jaka przypada na pojedynczy cykl sygnalizacyjny. W obu tych modelach występują dwa estymatory, odpowiedzialne za szacowanie średnich długości kolejek. Pierwszą z nich jest średnia długość kolejki formującej się z pojazdów zatrzymujących się na wlocie $w$ trakcie nadawania sygnału czerwonego i jeszcze częściowo na początku sygnału zielonego (wg definicji), nazywana kolejką na czerwonym świetle $K_{C}$. Drugą zaś jest średnia długość kolejki pojazdów, formująca się w poprzednim cyklu sygnalizacyjnym $\mathrm{w}$ wyniku zarówno braku zdolności obsługi pojazdów z kolejki $K_{C}$, jak i dojeżdżających do wlotu pojazdów w trakcie nadawania sygnału zielonego, nazywana kolejką pozostającą $K_{P}$. Suma tych dwóch wartości odpowiada średniej długości kolejki maksymalnej $K_{M}$. Różnica obu tych metod polega na tym, że model krajowy zakłada brak pojazdów na wlocie na początku sygnału czerwonego poprzedniego cyklu. Nie uwzględnia zatem faktu występowania tzw. kolejki początkowej $K_{0}$, która mogłaby się utworzyć przed analizowanymi cyklami sygnalizacyjnymi. Metoda HCM2000 natomiast uwzględnia kolejkę $K_{0}$, zarówno w estymatorze $K_{P}$, jak i przy ustalaniu natężenia potoku pojazdów dopływających do wlotu skrzyżowania $q$. Wartym uwagi jest, że w załączniku do polskich wytycznych znajduje się identyczny model szacowania wartości $K_{0}$, jak w metodzie HCM2000. Ma on jednak obecnie wyłącznie zastosowanie do wieloprzedziałowych analiz strat czasu. 
Metoda HCM2010 natomiast posiada odmienną konstrukcję modelu matematycznego szacowania średniej długości kolejki maksymalnej. Model wykorzystuje trzy estymatory, odpowiedzialne za szacowanie długości kolejek pojazdów:

- całkowicie zatrzymanych w trakcie trwania pojedynczego cyklu sygnalizacyjnego (utożsamiany z $K_{C}$ ),

- pozostających w danym cyklu (utożsamiany z $K_{P}$ ),

- pozostających w danym cyklu na wlocie na skutek obecności $K_{0}$.

Żaden z wyżej scharakteryzowanych modeli matematycznych nie posiada metody szacowania długości kolejek pojazdów w analizie wieloprzedziałowej.

\section{Badania terenowe długości kolejek pojazdów}

Do badań wybrano wlot ulicy Spornej na skrzyżowaniu tej ulicy z ulicą Fordońską w Bydgoszczy. Jest to skrzyżowanie o ruchu sterowanym sygnalizacją świetlną w stałym, cyklicznym programie sterowania. Długość cyklu sygnalizacyjnego równa była $120 \mathrm{~s}$, natomiast długość nadawania sygnału czerwonego wynosiła 90 s, zaś zielonego - 26 s (dane dotyczą okresu, w którym przeprowadzono badania). Badany wlot posiada jedną obliczeniową grupę pasów ruchu z jednym pasem ruchu, z której wjazd na skrzyżowanie odbywa się tylko w jednej relacji skrętnej.

Badaniom podlegały:

- natężenia oraz struktura rodzajowa strumieni pojazdów dojeżdżających do badanego wlotu skrzyżowania w przekroju wylotu sąsiedniego skrzyżowania;

- natężenia oraz struktura rodzajowa strumieni pojazdów opuszczających badany wlot skrzyżowania w przekroju linii zatrzymań po zapaleniu światła zielonego przez sygnalizator;

- długości kolejki pojazdów formującej się w trakcie nadawania sygnału czerwonego w danym cyklu sygnalizacyjnym;

- długości kolejki pojazdów pozostających z kolejki na świetle czerwonym z danego cyklu sygnalizacyjnego na cykl następny (które nie zdołały opuścić skrzyżowania w czasie nadawania sygnału zielonego) formując tzw. kolejkę pozostającą.

Badania były realizowane przez kilka dni roboczych. Wyniki badań zagregowane zostały w interwały 5-minutowe. Taki okres analizy sugerowany jest w wielu pozycjach literaturowych jako najbardziej odpowiedni do analiz warunków ruchu na skrzyżowaniach miejskich, charakteryzujących się dużą zmiennością natężeń ruchu w czasie. Dla tych przedziałów czasowych określono wszystkie parametry ruchu, istotne $\mathrm{w}$ toku analiz. 


\section{Analizy wyników badań}

Na rys. 1 przedstawiono przykładowe wyniki średnich długości kolejek maksymalnych $K_{M}$, uzyskane na podstawie badań na tle wartości szacowanych za pomocą poszczególnych modeli matematycznych [2, 3 i 4] (oznaczenie w legendzie rysunku ,bez $K_{0}$ ” oznacza bez uwzględnienia kolejki początkowej). Przedstawione na tym rysunku dane empiryczne prezentują zmiany w czasie długości kolejki pojazdów z jednego dnia pomiarowego (28 kwietnia 2014 r.) w okresie porannego szczytu przewozowego $\left(5^{00}-9^{00}\right)$.

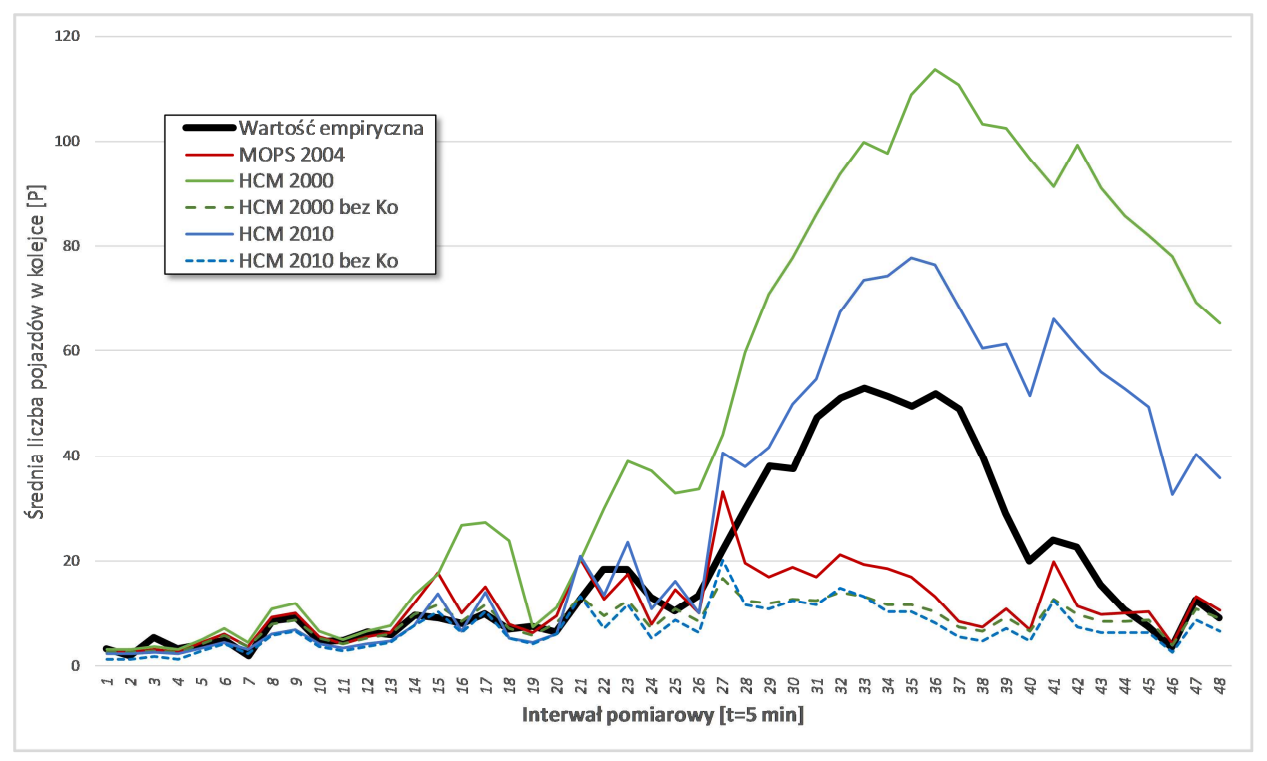

Rys. 1. Średnie obliczeniowe długości maksymalnych kolejek pojazdów na tle wartości empirycznych w 5-minutowym interwale pomiarowym

Fig. 1. The comparison of the average back-of-queue size, obtained from research and formulas included in the guidelines (5-minute interval measurement)

Zauważyć należy wyraźny podział na dwa podokresy. Pierwszy, w którym wartości empiryczne są w miarę zbieżne $\mathrm{z}$ wartościami teoretycznymi (z wyjątkiem metody HCM2000). Występuje on od 1 do 24 interwału pomiarowego, czyli w godzinach $5^{00}-7^{00}$. Do 24 interwału pomiarowego warunki ruchowe na skrzyżowaniu były na tyle korzystne, że nie przyczyniły się do wystąpienia kolejek pozostających (świadczących o przesyceniu wlotu).

W przypadku drugiego podokresu analizy (interwały $25 \div 48$ ), wyniki teoretyczne są albo niedoszacowane (modele bez uwzględniania wartości $K_{0}$ ), albo przeszacowane (modele uwzględniające wartości $K_{0}$ ). Niedoszacowanie wynika $\mathrm{z}$ tego, że w modelach tych całkowicie pomijane są warunki ruchowe, jakie występowały na wlocie w okresie poprzedzającym okres analizy. Przeszacowanie 
natomiast spowodowane jest ciągłym sumowaniem następujących po sobie wartości $K_{0}$ (z kolejnych interwałów). Modele matematyczne bowiem, uwzględniające szacowanie $K_{0}$, w okresach stanu przesycenia (gdy natężenie ruchu przekracza przepustowość wlotu) w sposób nieprzerwany dodają do siebie obliczeniowe długości kolejki początkowej z poprzednich okresów. Nie uwzględnia się w nich natomiast procesu, który autorzy nazwali ,procesem wchłaniania kolejki przez wlot". Polega on na zmniejszaniu się kolejki pozostającej w poprzednich okresach w sytuacji chwilowych stanów niedosycenia ruchem wlotu (natężenie ruchu na wlocie jest mniejsze od przepustowości wlotu). Stąd też skumulowane wyniki obliczeń są tak przeszacowane, co doskonale zauważyć można na rys. $1 \mathrm{w}$ okresie od 26 do 38 interwału pomiarowego.

Ponieważ średnia długość kolejki początkowej $K_{0}$ jest tożsama ze średnią długością kolejki pozostającej $K_{P}$ występującej w okresie poprzedzającym, wysunięto wniosek, że na błąd szacowania wartości $K_{M}$ głównie wpływ ma nieuwzględnianie lub błędne szacowanie wartości $K_{0}$.

Średniokwadratowe błędy szacowania za pomocą analizowanych metod obliczeniowych względem przedstawionych wyników badań zestawiono w tabl. 1 .

Tablica 1. Wyniki analiz różnic średnich długości kolejek pojazdów otrzymanych empirycznie i teoretycznie [P]

Table 1. Mean squared errors of back-of-queue size [veh.]

\begin{tabular}{|c|c|c|c|c|c|c|c|c|c|c|c|c|}
\hline \multirow{3}{*}{ Miara } & \multicolumn{12}{|c|}{ Parametr poddany ocenie } \\
\hline & \multicolumn{3}{|c|}{$K_{0}$} & \multicolumn{3}{|c|}{$K_{C}$} & \multicolumn{3}{|c|}{$K_{P}$} & \multicolumn{3}{|c|}{$K_{M}$} \\
\hline & 01 & O2 & $\Sigma$ & 01 & $\mathrm{O} 2$ & $\Sigma$ & 01 & 02 & $\Sigma$ & 01 & $\mathrm{O} 2$ & $\Sigma$ \\
\hline \multicolumn{13}{|c|}{ Wytyczne krajowe MOPS2004 [2] } \\
\hline$\overline{\bar{x}}$ & 0,9 & $-25,7$ & $-16,4$ & $-0,2$ & $-0,6$ & $-0,4$ & $-1,0$ & 12,5 & 7,5 & $-1,2$ & 12,0 & 7,0 \\
\hline$\widehat{\boldsymbol{\theta}}$ & 2,1 & 15,0 & 17,0 & 1,4 & 1,7 & 1,6 & 1,3 & 15,4 & 13,8 & 2,5 & 15,4 & 13,8 \\
\hline \multicolumn{13}{|c|}{ Wytyczne amerykańskie HCM2000 [3] $\left(K_{C}, K_{P} i K_{M} z\right.$ pominięciem szacowania $\left.K_{0}\right)$} \\
\hline$\overline{\boldsymbol{x}}$ & $-0,9$ & $-25,7$ & $-16,4$ & $-0,11$ & 0,09 & 0,01 & $-2,0$ & 11,2 & 6,2 & $-2,5$ & $-5,0$ & $-4,1$ \\
\hline$\widehat{\boldsymbol{\theta}}$ & 2,1 & 15,0 & 17,0 & 1,17 & 1,47 & 1,35 & 1,6 & 15,4 & 13,7 & 2,9 & 10,9 & 8,8 \\
\hline \multicolumn{13}{|c|}{ Vytyczne amerykańskie HCM2010 [4] $\left(K_{C}, K_{P} i K_{M} z\right.$ pominięciem szacowania $\left.K_{0}\right)$} \\
\hline $\bar{x}$ & $-3,2$ & $-19,3$ & $-13,2$ & 1,4 & 3,0 & 2,4 & $-0,4$ & 13,9 & 8,5 & 1,5 & 17,0 & 11,2 \\
\hline$\widehat{\boldsymbol{\theta}}$ & 11,7 & 15,5 & 16,1 & 1,1 & 1,8 & 1,8 & 0,7 & 15,5 & 14,0 & 1,2 & 15,5 & 14,4 \\
\hline \multicolumn{13}{|c|}{ Wytyczne amerykańskie HCM2000 [3] } \\
\hline$\overline{\bar{x}}$ & $-0,9$ & $-25,7$ & $-16,4$ & $-0,5$ & $-16,2$ & $-10,3$ & $-3,7$ & $-29,3$ & $-19,8$ & 4,4 & 45,5 & 30,1 \\
\hline$\widehat{\boldsymbol{\theta}}$ & 2,1 & 15,0 & 17,0 & 1,6 & 10,6 & 11,4 & 5,1 & 16,3 & 18,1 & 6,5 & 24,6 & 28,2 \\
\hline \multicolumn{13}{|c|}{ Wytyczne amerykańskie HCM2010 [4] } \\
\hline$\overline{\bar{x}}$ & $-3,2$ & $-19,3$ & $-13,2$ & 1,4 & 3,0 & 2,4 & $-0,4$ & 13,9 & 8,5 & 0,6 & $-18,7$ & $-11,4$ \\
\hline$\widehat{\boldsymbol{\theta}}$ & 11,7 & 15,5 & 16,1 & 1,1 & 1,8 & 1,8 & 0,7 & 15,5 & 14,0 & 2,1 & 15,0 & 15,2 \\
\hline \multicolumn{13}{|c|}{ 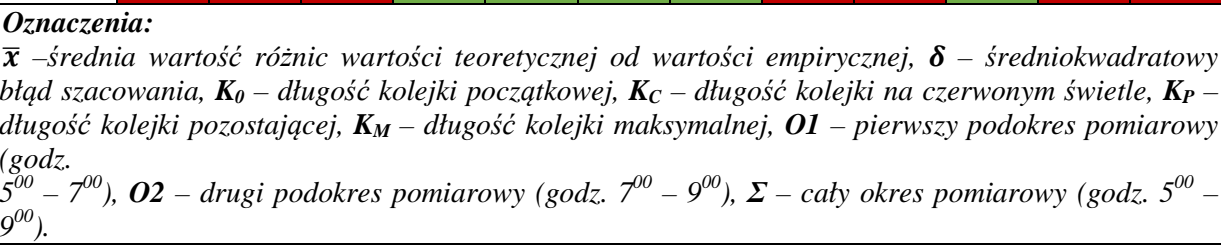 } \\
\hline
\end{tabular}


$\mathrm{Na}$ ich podstawie stwierdza się, że największe błędy szacowania dotyczą średniej długość kolejki początkowej. Przy braku danych o kolejkach początkowych modele matematyczne [2, 3 i 4] posiadają zbliżony do siebie błąd szacowania. Bardzo mały błąd szacowania występuje natomiast przy określaniu średniej długości kolejki na czerwonym świetle.

Wobec powyższego, autorzy dokonali weryfikacji poddanych analizie modeli matematycznych, w których zastosowano empiryczne wartości średniej długości kolejki początkowej $K_{0, \text { emp }}$. Rezultat tej analizy zilustrowano na rys. 2 (oznaczenie w legendzie rysunku „, $K_{0, \text { emp }}$ " oznacza uwzględnianie empirycznej długości kolejki początkowej). Natomiast średniokwadratowe błędy szacowania zestawiono w tabl. 2.

Dokonując analizy wyników, które zaprezentowano na rys. 2 i w tabl. 2 stwierdza się, że uwzględniając w analizach rzeczywistą długość kolejki początkowej $K_{0}$ uzyskuje się nieduże błędy szacowania długości kolejki $K_{M}$. Praktycznie pomijana w analizach krajowych składowa wzoru $K_{0}$ okazuje się być najistotniejszym elementem estymatora $K_{M}$. Najważniejszym problemem badawczym powinno być zatem właściwe ustalenie modelu obliczeniowego średniej długości kolejki początkowej.

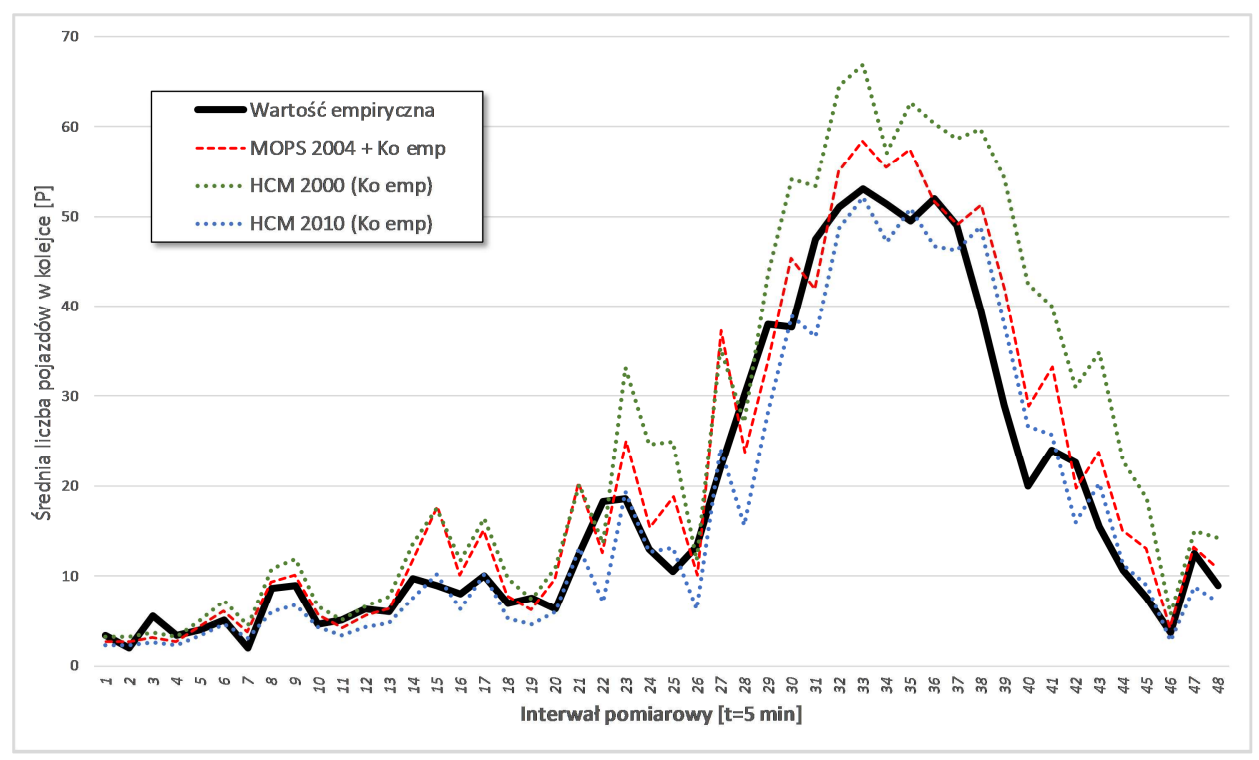

Rys. 2. Analiza średnich długości maksymalnych kolejek pojazdów z wykorzystaniem empirycznych wartości $K_{0}$ na tle wartości empirycznych w 5-minutowym interwale pomiarowym

Fig. 2. The comparison of the average back-of-queue size using the empirical $K_{0}$ value, obtained from research and formulas included in the guidelines (5-minute interval measurement) 
Tablica 2. Wyniki analiz różnic średnich długości kolejek pojazdów otrzymanych empirycznie i teoretycznie $[\mathrm{P}] \mathrm{z}$ wykorzystaniem empirycznych wyników średniej długości kolejki początkowej

Table 2. Mean squared errors back-of-queue size [veh.] using the empirical initial queues value

\begin{tabular}{|c|c|c|c|c|c|c|c|c|c|}
\hline \multirow{3}{*}{ Miara } & \multicolumn{9}{|c|}{ Parametr poddany ocenie } \\
\hline & \multicolumn{3}{|c|}{$K_{C}$} & \multicolumn{3}{|c|}{$K_{P}$} & \multicolumn{3}{|c|}{$K_{M}$} \\
\hline & 01 & 02 & $\Sigma$ & 01 & 02 & $\Sigma$ & 01 & 02 & $\Sigma$ \\
\hline \multicolumn{10}{|c|}{ Wytyczne krajowe MOPS2004 [2] $\left(K_{M}+K_{0, e m p}\right)$} \\
\hline $\bar{x}$ & $-0,2$ & $-0,6$ & $-0,4$ & $-1,0$ & 12,5 & 7,5 & $-1,2$ & $-3,6$ & $-2,7$ \\
\hline$\widehat{\boldsymbol{\theta}}$ & 1,4 & 1,7 & 1,6 & 1,3 & 15,4 & 13,8 & 2,5 & 5,7 & 4,9 \\
\hline \multicolumn{10}{|c|}{ Wytyczne amerykańskie HCM2000 [3] } \\
\hline $\bar{x}$ & $-2,0$ & $-3,5$ & $-2,9$ & $-0,2$ & $-6,3$ & $-4,0$ & $-2,2$ & $-9,8$ & $-6,9$ \\
\hline$\widehat{\boldsymbol{\theta}}$ & 1,6 & 7,1 & 5,7 & 1,2 & 6,6 & 6,0 & 2,5 & 7,5 & 7,1 \\
\hline \multicolumn{10}{|c|}{ Wytyczne amerykańskie HCM2010 [4] } \\
\hline$\overline{\bar{x}}$ & 1,4 & 3,0 & 2,4 & $-0,4$ & 13,9 & 8,5 & 1,1 & 1,4 & 1,3 \\
\hline$\widehat{\boldsymbol{\theta}}$ & 1,1 & 1,8 & 1,6 & 0,7 & 15,5 & 14,0 & 1,2 & 5,6 & 4,5 \\
\hline
\end{tabular}

Z dokonanej analizy wynika, że najbardziej dokładnym modelem, za pomocą którego uzyskiwany jest najmniejszy średniokwadratowy błąd szacowania, jest estymator kolejek metody HCM2010. Średnia wartość różnicy wartości teoretycznej od empirycznej jest niewielka i dodatnia - co oznacza, że otrzymywane rezultaty w większości przypadków są tylko nieznacznie niedoszacowane.

\section{Wnioski}

Na podstawie przeprowadzonych wyników badań stwierdzono słuszność podjętej tematyki analizy procesu zmian długości kolejek pojazdów na wlotach skrzyżowań z sygnalizacją świetlną. Obecne metody szacowania, w tym przede wszystkim obowiązujący w kraju model obliczeniowy średniej długości kolejek pojazdów, nie są poprawne.

Niewątpliwym mankamentem we wszystkich metodach wyznaczania średniej długości kolejki pojazdów jest błędne szacowanie średniej długości kolejki pozostającej, w tym głównie błędne szacowanie średniej długości kolejki początkowej (dotyczy to również wzoru Z1.6 przedstawionego w załączniku do polskich wytycznych [2]). Obie te wartości są niezwykle istotne w przypadku analiz wieloprzedziałowych, w których obserwuje się zjawisko przenoszenia się kolejek pomiędzy następującymi po sobie cyklami sygnalizacyjnymi, gdy mamy do czynienia $\mathrm{z}$ nadwyżką natężenia ruchu na dojeździe do sterowanego wlotu skrzyżowania w stosunku do przepustowości tego wlotu. $Z$ wyżej nakreślonych powodów autorzy niniejszej pracy uznali za najważniejsze zadanie badawcze opracowanie poprawnych modeli matematycznych wielkości $K_{0}$ i $K_{P}$.

Należy podkreślić także duże znaczenie wielkości przyjmowanego okresu do analiz na dokładność szacowania długości kolejek, szczególnie w stanach dużego nasycenia ruchem. Sugerowany do obliczeń np. w polskiej metodzie [2] 
okres 15 minut (lub 1 godziny) jest bez wątpienia zbyt duży, powoduje bowiem znaczne zaniżanie wyników obliczeń i tym samym większe błędy przy wyznaczaniu długości kolejek pojazdów.

\section{Literatura}

[1] Deloitte, Targeo.pl: Raport o korkach w 7 największych miastach Polski. Dane za rok 2015. Warszawa 2016.

[2] Generalna Dyrekcja Dróg Krajowych i Autostrad w Warszawie: Metoda obliczania przepustowości skrzyżowań z sygnalizacją świetlna. Instrukcja obliczania. Politechnika Krakowska, Warszawa 2004.

[3] Transportation Research Board: High Capacity Manual. HCM 2000. National Academy of Sciences, United States of America, 2000.

[4] Transportation Research Board: High Capacity Manual. HCM 2010. National Academy of Sciences, United States of America, 2010.

[5] Szczuraszek T., Iwanowicz D.: The analysis of calculation methods of vehicle queue lengths in front of intersection inlets with traffic lights. Logistyka, $\mathrm{nr}$ 4/2015.

\section{DILEMMAS IN THE DETERMINATION OF OVERSATURATION STATE ON INTERSECTION INLETS WITH TRAFFIC LIGHTS}

\section{S u m m a r y}

The article presents an analysis of the accuracy of estimating the average back-of-queue size on the intersection inlets with traffic lights, using mathematical models in the Polish and US guidelines. Based on own research the authors found, that errors of estimating queue lengths are very significant in the case of high traffic density or oversaturation state on inlets. The main reason for this is non-included or improper method of determining the initial queues, formed in the previous period compared to the current period of the analysis.

Keywords: back-of-queue, traffic lights, traffic congestion

Przestano do redakcji: $07.06 .2016 r$.

Przyjęto do druku: 30.06.2016 r.

DOI: $10.7862 / \mathrm{rb} .2016 .77$ 